\title{
Voltage-Gated Sodium Channels Mediating Conduction in Vagal Motor Fibers Innervating the Esophageal Striated Muscle
}

\author{
Nikoleta PAVELKOVA ${ }^{1,2}$, Mariana BROZMANOVA ${ }^{1}$, Mayur JAYANTA PATIL ${ }^{2}$, Marian \\ KOLLARIK ${ }^{2}$
}

${ }^{1}$ Department of Pathophysiology, Jessenius Faculty of Medicine, Comenius University, Martin, Slovak Republic, ${ }^{2}$ Department of Molecular Pharmacology and Physiology, Morsani College of Medicine, University of South Florida, Tampa, Florida, USA

Received March 30, 2020

Accepted October 6, 2020

\section{Summary}

The vagal motor fibers innervating the esophageal striated muscle are essential for esophageal motility including swallowing and vomiting. However, it is unknown which subtypes of voltagegated sodium channels ( $\mathrm{Nav} 1 \mathrm{~s})$ regulate action potential conduction in these efferent nerve fibers. The information on the Nav1s subtypes is necessary for understanding their potential side effects on upper gut, as novel inhibitors of Nav1s are developed for treatment of pain. We used isolated superfused $\left(35^{\circ} \mathrm{C}\right)$ vagally-innervated mouse esophagus striated muscle preparation (mucosa removed) to measure isometric contractions of circular striated muscle evoked by electrical stimulation of the vagus nerve. Nav1 inhibitors were applied to the de-sheathed segment of the vagus nerve. Tetrodotoxin (TTX) applied to the vagus nerve completely abolished electrically evoked contractions. The selective $\mathrm{Na}_{v} 1.7$ inhibitor PF-05089771 alone partially inhibited contractions and caused a >3-fold rightward shift in the TTX concentration-inhibition curve. The Nav1.1, $\mathrm{Na}_{v} 1.2$ and Nav1.3 group inhibitor ICA-121431 failed to inhibit contractions, or to alter TTX concentration-inhibition curves in the absence or in the presence of PF-05089771. RT-PCR indicated lack of $\mathrm{Na}_{\mathrm{v}} \mathrm{1.4}$ expression in nucleus ambiguus and dorsal motor nucleus of the vagus nerve, which contain motor and preganglionic neurons projecting to the esophagus. We conclude that the action potential conduction in the vagal motor fibers to the esophageal striated muscle in the mouse is mediated by TTX-sensitive voltage gated sodium channels including Nav1.7 and most probably Nav1.6. The role of Nav1.6 is supported by ruling out other TTX-sensitive Nav1s (Nav1.1-1.4) in the Nav1.7-independent conduction.

\section{Key words}

Voltage-gated sodium channels • Vagal motor fibers • Esophageal striated muscle $\bullet$ Action potential conduction

\section{Corresponding author}

M. Brozmanova, Department of Pathophysiology, Jessenius Faculty of Medicine, Comenius University, Mala Hora C, 03601 Martin, Slovak Republic. E-mail: mariana.brozmanova@uniba.sk

\section{Introduction}

Esophageal muscle is the effector of esophageal motility, including swallowing, esophageal sphincters function and vomiting. An important portion of the proximal esophageal muscle is composed of striated muscle. The esophageal striated muscle is directly controlled by brainstem efferent vagal motor neurons which project axons into the esophagus, forming neuromuscular junctions on the striated muscle fibers (Neuhuber et al. 2006). The action potentials originating in the neuronal cell bodies of these motor neurons are conducted along the axons to the neuromuscular junctions initiating contractions of the striated muscle. This conduction is dependent on the voltage-gated sodium channels $\left(\mathrm{Na}_{\mathrm{V}} 1 \mathrm{~s}\right)$. However, of the various $\mathrm{Na}_{\mathrm{V}} 1$ types the specific $\mathrm{Na}_{\mathrm{V}} 1 \mathrm{~s}$ that are responsible for the conduction of action potentials in vagal motor fibers to esophageal striated muscle remain unknown.

The 9 subtypes of $\mathrm{Na}_{\mathrm{V}} 1 \mathrm{~s}$ in mammals are differentiated by their pore-forming $\alpha$ subunits denoted as $\mathrm{Na}_{V} 1.1$ through $\mathrm{Na}_{\mathrm{V}} 1.9$ (Catterall 2012). Certain $\mathrm{Na}_{\mathrm{V}} 1 \mathrm{~s}$

PHYSIOLOGICAL RESEARCH • ISSN 1802-9973 (online) 
are preferentially expressed in specific cell types, such as $\mathrm{Na}_{\mathrm{V}} 1.4$ in the skeletal muscle and $\mathrm{Na}_{\mathrm{V}} 1.5$ in the cardiac muscle. However, both central and peripheral neurons express different combinations of $\mathrm{Na}_{\mathrm{V}} 1 \mathrm{~s}$. Until recently, it was difficult to evaluate the role of individual $\mathrm{Na}_{\mathrm{V}} 1 \mathrm{~s}$ in neurons due to limited physiological and pharmacological tools to discriminate $\mathrm{Na}_{\mathrm{V}} 1 \mathrm{~s}$ subtypes. Fortunately, the progress in last few years, in particular the validation of selective $\mathrm{Na}_{\mathrm{V}} 1 \mathrm{~s}$ inhibitors has enabled a more detailed analysis (McCormack et al. 2013, Alexandrou et al. 2016, Swain et al. 2017).

$\mathrm{Na}_{\mathrm{V}} 1 \mathrm{~s}$ that are critical for the function of peripheral pain-mediating nerves (nociceptors) can be targeted for the treatment of pain (Bennett et al. 2019). Therefore, peripherally acting $\mathrm{Na}_{\mathrm{V}} 1$ inhibitors, that do not have CNS side effects like the centrally acting analgesics such as opioids, are being developed. However, the $\mathrm{Na}_{\mathrm{V}} \mathrm{l}$ inhibitors acting on the peripheral nerve terminals can produce unwanted side effects by acting on other peripheral nerve types. Thus, it is important to elucidate the type of $\mathrm{Na}_{\mathrm{V}} 1 \mathrm{~s}$ that regulate esophageal motility. Here we aimed to identify the $\mathrm{Na}_{\mathrm{V}} 1 \mathrm{~s}$ that underlay the action potential conduction in motor fibers to esophageal striated muscle.

\section{Materials and Methods}

\section{Contraction studies}

Animal protocol was approved by the University of South Florida IACUC. The animals were held in airconditioned animal holding facility with controlled room temperature and humidity with alternating $12 \mathrm{~h}$ light/dark cycle and other physiological needs to maintain animal welfare. At all times, the animals had free access to food and water. Mice (C57BL/6J male, 5-7 weeks old) were euthanized by inhalation of $100 \% \mathrm{CO}_{2}$ followed by exsanguination. The esophagus was dissected out with the vagus nerve attached. The mucosa was removed (pulled out) from inside of the esophagus while circular and longitudinal striated muscle layers were preserved intact. The vagus nerve were cleaned and de-sheathed $(10-15 \mathrm{~mm})$ to enable drug access to the nerve. The esophagus-vagus nerve preparation was placed in a Sylgard-lined organ bath chamber (Fig. 1, volume $50 \mathrm{ml}$ ) and superfused (superfusion rate $10 \mathrm{ml} / \mathrm{min}$ ) with gassed $\left(95 \% \mathrm{O}_{2} / 5 \% \mathrm{CO}_{2}\right)$ Krebs bicarbonate solution (KBS) (mM): $118 \mathrm{NaCl}, \quad 5.4 \mathrm{KCl}, \quad 1 \mathrm{NaH}_{2} \mathrm{PO}_{4}$, 1.2 $\mathrm{MgSO}_{4}, 1.9 \mathrm{CaCl}_{2}, 25 \mathrm{NaHCO}_{3}$ and 11.1 dextrose containing indomethacin $3 \mu \mathrm{M}$ ) at $35^{\circ} \mathrm{C}$. For the isometric contraction studies the esophagus was stretched laterally by using two metal triangles as shown in Figure 1. One metal triangle was pinned to the bottom of the esophagus chamber while the other triangle was connected with a silk suture to calibrated isometric force transducer (FORT250, WPI, Sarasota, FL, USA). The signal was amplified by pre-amplifier (Transbridge TBM4M, WPI), digitalized by Micro 1403 (CED, Cambridge, England) and recorded and analyzed by Spike 2 software (CED). The contractions were measured under isometric conditions and the readout was the force of the contraction expressed in miliNewtons $(\mathrm{mN})$. Rostral portion of the vagus nerve was pulled into separately superfused de-sheathed vagus nerve chamber (Fig. 1, volume $2 \mathrm{ml}$, superfusion rate $1.5 \mathrm{ml} / \mathrm{min}$ ). Concentric stimulating platinum-iridium electrode (PI-NE-100, MicroProbes, Gaithersburg, MD, USA) was placed onto the nerve and used to electrically stimulate the vagus nerve (Fig. 1). Electrical pulses were generated by isolated pulse stimulator (Model 2100 AM-Systems, Sequim, WA). KBS in all reservoirs used for perfusion of tissue chambers and for drug preparation as well as KBS in the esophagus chamber was constantly gassed with $\begin{array}{lllllll}95 & \% & \mathrm{O}_{2} / 5 & \% & \mathrm{CO}_{2} & \text { mixture via diffuser air stones }\end{array}$ throughout the whole experiment. The esophagus was equilibrated for at least $30 \mathrm{~min}$ while being stretched to $2 \mathrm{mN}$ (with $0.2 \mathrm{~g}$ ) and until the $2 \mathrm{mN}$ tension was stable for at least $15 \mathrm{~min}$. The vagus nerve was then stimulated with electrical pulses (duration $1 \mathrm{~ms}$, frequency $1 \mathrm{pulse} / \mathrm{min})$ with increasing voltage $(1,3,5,7,10,15$ and $20 \mathrm{~V}$ ) to determine the voltage effective to evoke maximum esophageal contraction. This voltage ( 7 or $10 \mathrm{~V}$ in most preparations, except $5 \mathrm{~V}$ in one preparation) was then used for stimulation during the whole experiment. In most experiments, the left vagus nerve was used. In few experiments in which maximally effective electrical stimulation failed to evoke contractions of at least $5 \mathrm{mN}$ (attributed to nerve damage during de-sheathing), the right vagus nerve was used. The force of contraction evoked by a single pulse $(11 \pm 1 \mathrm{mN})$ was essentially identical to the averaged force of contractions evoked by the pulse train $(11 \pm 1 \mathrm{mN})(\mathrm{N}=23$, N.S. Paired $t$-test). In control experiments and during the incubation with $\mathrm{Na}_{\mathrm{V}} 1$ inhibitors the vagus nerve was stimulated at the frequency of 1 pulse/min for $30 \mathrm{~min}$ followed by a train of 15 pulses at $1 \mathrm{~Hz}$. This paradigm was chosen to evaluate the effect on conduction not only at single pulse, but also at repetitive stimulation. Firstly, the baseline was established after the control perfusion of 

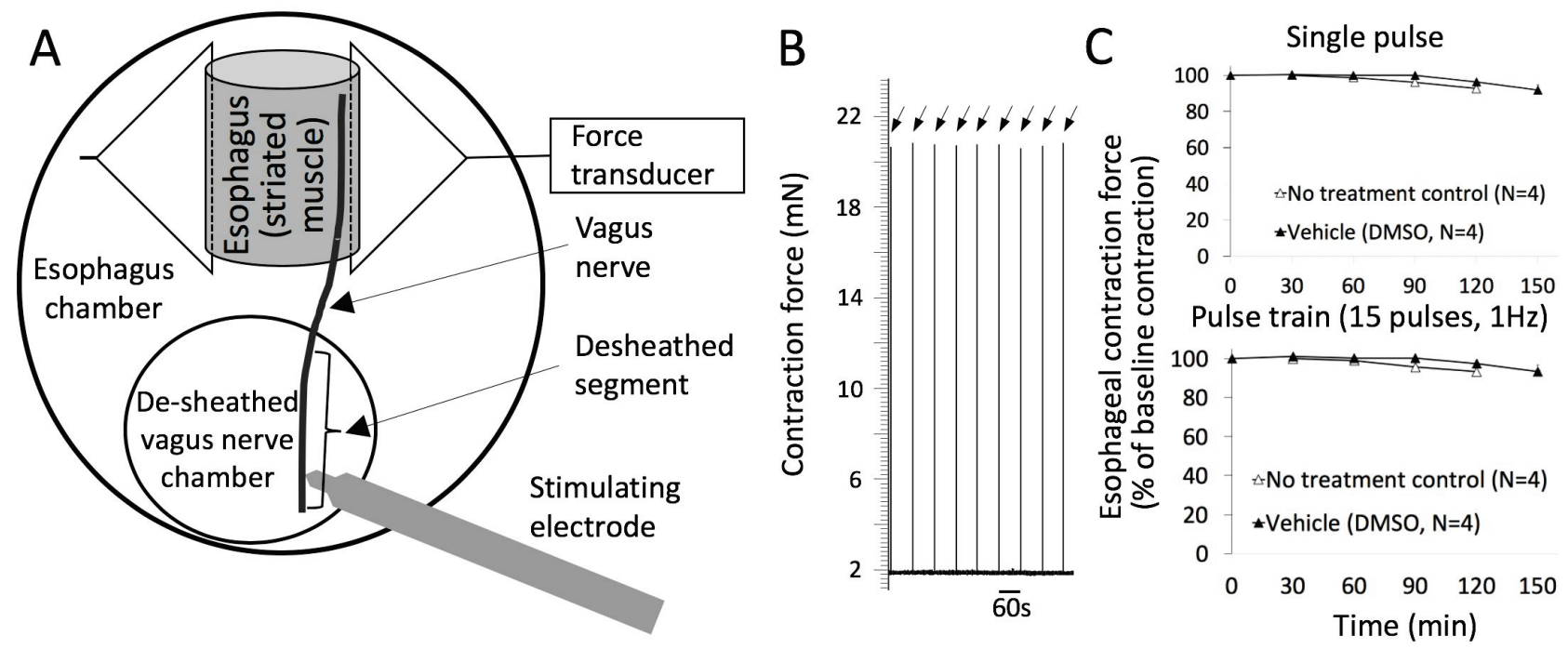

Fig. 1. Isolated vagally-innervated esophageal striated muscle preparation for the study of voltage-gated sodium channels mediating action potential conduction in vagal motor fibers innervating esophageal striated muscle. (A) Schematic drawing of the experiment. Contractions of esophageal striated muscle were evoked by electrical stimulation of the vagus nerve containing motor fibers. The Nav1 inhibitors were applied in the de-sheathed vagus nerve chamber which was superfused separately from the esophageal chamber to avoid exposure of esophageal muscle to Nav1 inhibitors. (B) Representative trace of reproducible esophageal contractions evoked by single supramaximal pulse applied every 60s in control conditions. Arrows indicate timing of the pulse. (C) Reproducibility of esophageal contractions for single pulse and pulse trains over time in control conditions (no treatment) and in the presence of vehicle ( $0.13 \%$ DMSO).

de-sheathed vagus nerve chamber with KBS for 30 min. Then, the different $\mathrm{Na}_{\mathrm{V}} 1$ inhibitors were applied to desheathed vagus nerve chamber (Fig. 1) in superfusing KBS diluted to indicated concentrations. The $\mathrm{Na}_{\mathrm{V}} 1$ inhibitor(s) were applied until a steady-state was reached in which the amplitude of contractions evoked by isolated pulses was stable for at least $5 \mathrm{~min}$. If $5 \mathrm{~min}$ of steadystate was reached in less than $30 \mathrm{~min}$ of application of $\mathrm{Na}_{\mathrm{V}} 1$ inhibitor(s), the application continued until the total time of application was $30 \mathrm{~min}$. The inhibition by the $\mathrm{Na}_{\mathrm{V}} 1$ inhibitor tetrodotoxin (TTX, 0, 0.01, 0.03 and $0.1 \mu \mathrm{M})$ and the combination of $\mathrm{Na}_{\mathrm{v}} 1$ inhibitors PF $050897713 \mu \mathrm{M}+\operatorname{TTX}(0,0.01,0.03$ and $0.1 \mu \mathrm{M})$, ICA $12143110 \mu \mathrm{M}+$ TTX $(0,0.01,0.03$ and $0.1 \mu \mathrm{M})$ and PF $050897713 \mu \mathrm{M}+$ ICA $12143110 \mu \mathrm{M}+\mathrm{TTX}(0$, $0.01,0.03$ and $0.1 \mu \mathrm{M})$ was evaluated in $4,5,5$ and 5 prepara-tions (1 preparation per animal), respectively. In the instances in which the combination of $\mathrm{Na}_{\mathrm{V}} 1$ inhibitors containing $0.03 \mu \mathrm{M}$ concentration of TTX completely blocked the contraction, the inhibition of contraction in the presence of the combination of inhibitors $\mathrm{Na}_{\mathrm{V}} 1$ containing the subsequent $0.1 \mu \mathrm{M}$ concentration of TTX could not be evaluated (since the contraction was already completely blocked). The time controls and the vehicle ( $0.13 \%$ DMSO) controls were evaluated in 4 and 4 preparations, respectively. The concentration of vehicle DMSO was calculated as the largest concentration used in our experiments when the combination of PF-05089771 $3 \mu \mathrm{M}$ (containing DMSO $3: 10,000, \quad 0.03 \%$ ), ICA-121431 $10 \mu \mathrm{M}$ (containing DMSO $1: 1,000,0.1 \%)$ and TTX $0.1 \mu \mathrm{M}(0 \%$ DMSO, dissolved in water) was used totaling $0.13 \%$ DMSO. The contraction in the presence of $\mathrm{Na}_{\mathrm{V}} 1$ inhibitor(s) and the control experiments was expressed as the percentage of baseline contraction.

Indomethacin (Sigma-Aldrich, St. Louis, MO, USA) was dissolved to $30 \mathrm{mM}$ stock solution in ethanol. ICA 121431 (Tocris Bioscience, Minneapolis, MN, USA) and PF 05089771 (Tocris Bioscience) were dissolved to $10 \mathrm{mM}$ stock solutions in dimethyl sulfoxide (DMSO, Sigma-Aldrich). Atropine (Sigma-Aldrich), tubocurarine (Tocris Bioscience) and tetrodotoxin (TTX, Alomone labs, Jerusalem, Israel) were dissolved to $100 \mathrm{mM}$, $10 \mathrm{mM}$ and $1 \mathrm{mM}$ stock solutions, respectively, in distilled water. The chemicals were diluted to final concentrations in KBS just prior to application.

The data are presented as mean +/- SEM. One-way ANOVA followed by Dunnett's multiple comparisons test was used to compare the effect of various $\mathrm{Na}_{\mathrm{v}} 1$ inhibitor(s) and their combinations.

\section{RT-PCR expression study}

Mice (C57BL/6J male, 5-7 weeks old) were euthanized by inhalation of $100 \% \mathrm{CO}_{2}$ followed by exsanguination. Left and right areas of brainstem containing dorsal motor nucleus (DMV) or nucleus 
ambiguus (NA) were dissected out and placed in separate tubes containing $700 \mu \mathrm{l}$ of QIAzol Lysis Reagent (QIAGEN, Germantown, MD, USA). RNA was isolated from tissue by the RNeasy Mini Kit (QIAGEN) according to manufacturer's instructions. RNA was converted into first-strand cDNA with the use of the SuperScript III First-Strand Synthesis System for RT-PCR (ThermoFisher-Invitrogen, Waltham, MA, USA) according to manufacturer's instructions. Total volume of $7 \mu \mathrm{l}$ of RNA was used in this reverse transcription reaction. cDNA was amplified in 30 cycles of denaturation $94{ }^{\circ} \mathrm{C}$ for $30 \mathrm{~s}$, annealing $60^{\circ} \mathrm{C}$ for $30 \mathrm{~s}$ and extension $72{ }^{\circ} \mathrm{C}$ for $1 \mathrm{~min}$ followed by a final extension $72{ }^{\circ} \mathrm{C}$ for $10 \mathrm{~min}$ using. The following customsynthesized (Bio-Synthesis, Lewisville, TX, USA) primers validated in our previous studies (Kocmalova et al. 2017) were used (NCBI Reference Sequence, forward primer, reverse primer, product size): $\beta$-actin (NM_007393.3, GTGGGAATGGGTCAGAAGG, GAGGCATACAGGGACAGCA, 302), Na 1.4 (NM_133199.2, TCATCTTCCTGGGTTCCTTC, ATCTGCCTCCTCTCCACCTT, 206), $\mathrm{Na}_{\mathrm{v}} 1.6$ (NM_001077499.2, AGGCAGCAAAGACAAACTGG, GCAGCACTTGAACCTCTGG, 157), Na 1.7 (NM_001290674.1, ATGCTCTTCTTTGCGGTTTC, CGGCTTCTTCCTGCTCTTTT, 381). Products were visualized in $1.5 \%$ agarose gel that was stained by GelRed and figures were assembled in PowerPoint.

\section{Results}

Our mouse vagally-innervated esophageal striated muscle preparation consists of the esophageal striated muscle (mucosa is removed as detailed in methods) and the attached vagus nerve (Fig. 1A). In this preparation electrical stimulation of the proximal end of the cervical vagus nerve with a single maximallyeffective pulse evokes rapid contraction of esophageal striated muscle (Fig. 1B, abolished by the muscular nicotinic receptors antagonist tubocurarine 3-10 $\mu \mathrm{M}, \mathrm{N}=4$ but not influenced by the muscarinic receptors antagonist atropine $1 \mu \mathrm{M}, \mathrm{N}=4$ applied to esophageal tissue compartment). The contractions of striated muscle occur because electrical stimulation of the vagus nerve evokes action potentials in motor fibers to esophageal striated muscle; these action potentials then propagate distally in the vagus nerve and trigger contractions upon arriving to esophageal striated muscle neuromuscular junctions. Thus, we can investigate the nature of $\mathrm{Na}_{\mathrm{V}} 1 \mathrm{~s}$ underlying conduction in motor fibers to esophageal striated muscle by applying $\mathrm{Na}_{\mathrm{V}} 1$ inhibitors to a segment of vagus nerve between the stimulating electrode and the esophageal striated muscle. If a $\mathrm{Na}_{\mathrm{V}} 1$ inhibitor inhibits conduction in the motor fibers to esophageal striated muscle, then the vagally-induced esophageal striated muscle contractions will be reduced.

The class-defining $\mathrm{Na}_{\mathrm{V}} 1$ inhibitor tetrodotoxin (TTX) applied to the vagus nerve abolished the vagally-induced esophageal striated muscle contractions (Fig. 2A). The effect of TTX was concentration-dependent with $\mathrm{EC}_{50}$ between $0.01-0.03 \mu \mathrm{M}$ and a complete block at $0.1 \mu \mathrm{M}$ (Fig. 2E). Thus, TTX-sensitive $\mathrm{Na}_{\mathrm{V}} 1 \mathrm{~s}$ are required for the conduction in motor fibers to esophageal striated muscle. The TTX-sensitive $\mathrm{Na}_{\mathrm{v}} 1 \mathrm{~s}$ are $\mathrm{Na}_{\mathrm{v}} 1.1,1.2,1.3,1.4,1.6$ and/or 1.7. Inasmuch as $\mathrm{Na}_{\mathrm{v}} 1.7$ was implicated in vagal efferent function (Kocmalova et al. 2017), we first evaluated the $\mathrm{Na}_{\mathrm{v}} 1.7$ blocker PF-05089771. In the concentration of $3 \mu \mathrm{M}$ which completely blocks mouse $\mathrm{Na}_{\mathrm{V}} 1.7$, PF-05089771 only modestly (by $17 \pm 3 \%$, $\mathrm{P}<0.05)$ inhibited vagally-induced esophageal striated muscle contractions (Fig. 2B). However, PF-05089771 $(3 \mu \mathrm{M})$ dramatically enhanced the inhibitory effect of TTX (Fig. 2E). Specifically, TTX $(0.01 \mu \mathrm{M})$ inhibited vagally-induced esophageal striated muscle contractions by $10 \pm 3 \%$ and $85 \pm 12 \%$ in the absence and presence of PF-05089771 $(3 \mu \mathrm{M})$, respectively (Fig. $2 \mathrm{E}, \mathrm{P}<0.01)$. These results indicate that $\mathrm{Na}_{\mathrm{V}} 1.7$ contributes to the conduction in motor fibers to esophageal striated muscle.

We next evaluated the effect of $\mathrm{Na}_{\mathrm{v}} 1.1 / 1.2 / 1.3$ group blocker ICA-121431. In the concentration of $10 \mu \mathrm{M}$ (expected to completely block mouse $\mathrm{Na}_{\mathrm{V}} 1.1,1.2$ and 1.3) ICA-121431 failed to inhibit contractions or to potentiate TTX (Fig. 2C, E). The role of ICA-121431inhibitable $\mathrm{Na}_{\mathrm{V}} 1 \mathrm{~s}$ was not unmasked in the presence of PF-05089771. Adding ICA-121431 to PF-05089771 did not have any additional effect on contractions and on TTX inhibition than PF-05089771 alone (Fig. 2D, E). Thus, $\mathrm{Na}_{\mathrm{V}} 1.1,1.2$ and 1.3 do not contribute to the action potential conduction in the motor fibers to the esophageal striated muscle. The results presented thus far (Fig. 2E) were obtained by analysis of contractions evoked by single pulses. We obtained identical results when we analyzed the effects of $\mathrm{Na}_{\mathrm{V}} 1 \mathrm{~s}$ inhibitors on $1 \mathrm{~Hz}$ pulse train (Fig. 2F).

As we ruled out $\mathrm{Na}_{\mathrm{v}} 1.1,1.2$ and 1.3 , by using ICA-121431, the conduction that is not mediated by $\mathrm{Na}_{V} 1.7$ must be mediated by $\mathrm{Na}_{V} 1.4$ and/or $\mathrm{Na}_{V} 1.6$ 
(the only remaining TTX-sensitive $\mathrm{Na}_{\mathrm{V}} 1 \mathrm{~s}$ ). Unfortunately, there are no selective inhibitors of $\mathrm{Na}_{\mathrm{V}} 1.4$ and $\mathrm{Na}_{\mathrm{V}} 1.6$ available. Therefore, we sought an alternative strategy. Given that $\mathrm{Na}_{\mathrm{V}} 1.4$ expression is largely restricted to the skeletal striated muscle, $\mathrm{Na}_{\mathrm{V}} 1.4$ is unlikely to be involved. Nonetheless, we hypothesized that if $\mathrm{Na}_{\mathrm{V}} 1.4$ is involved, it should be expressed in the brainstem nuclei, which contain neurons that project efferent motor fibers into the esophagus, namely nucleus ambiguous and dorsal motor nucleus of the vagus nerve (Neuhuber et al. 2006, McGovern et al. 2010). We performed RT-PCR on brainstem tissue containing dorsal motor nucleus of the vagus nerve $(\mathrm{N}=4)$ and nucleus ambiguus $(\mathrm{N}=4)$ from 4 different animals. We found that $\mathrm{Na}_{\mathrm{V}} 1.4$ was absent, although $\mathrm{Na}_{\mathrm{V}} 1.6$ and $\mathrm{Na}_{\mathrm{V}} 1.7$ were readily detected as expected (Fig. 3, only in 1 of 8 samples a faint $\mathrm{Na}_{\mathrm{V}} 1.4$ band was detectable with enhanced brightness and contrast). Thus, the lack of expression of $\mathrm{Na}_{\mathrm{V}} 1.4$ in brainstem areas containing neurons that project axons to the esophagus effectively rules out $\mathrm{Na}_{\mathrm{V}} 1.4$ in conducting action potentials to the esophageal striated muscle.
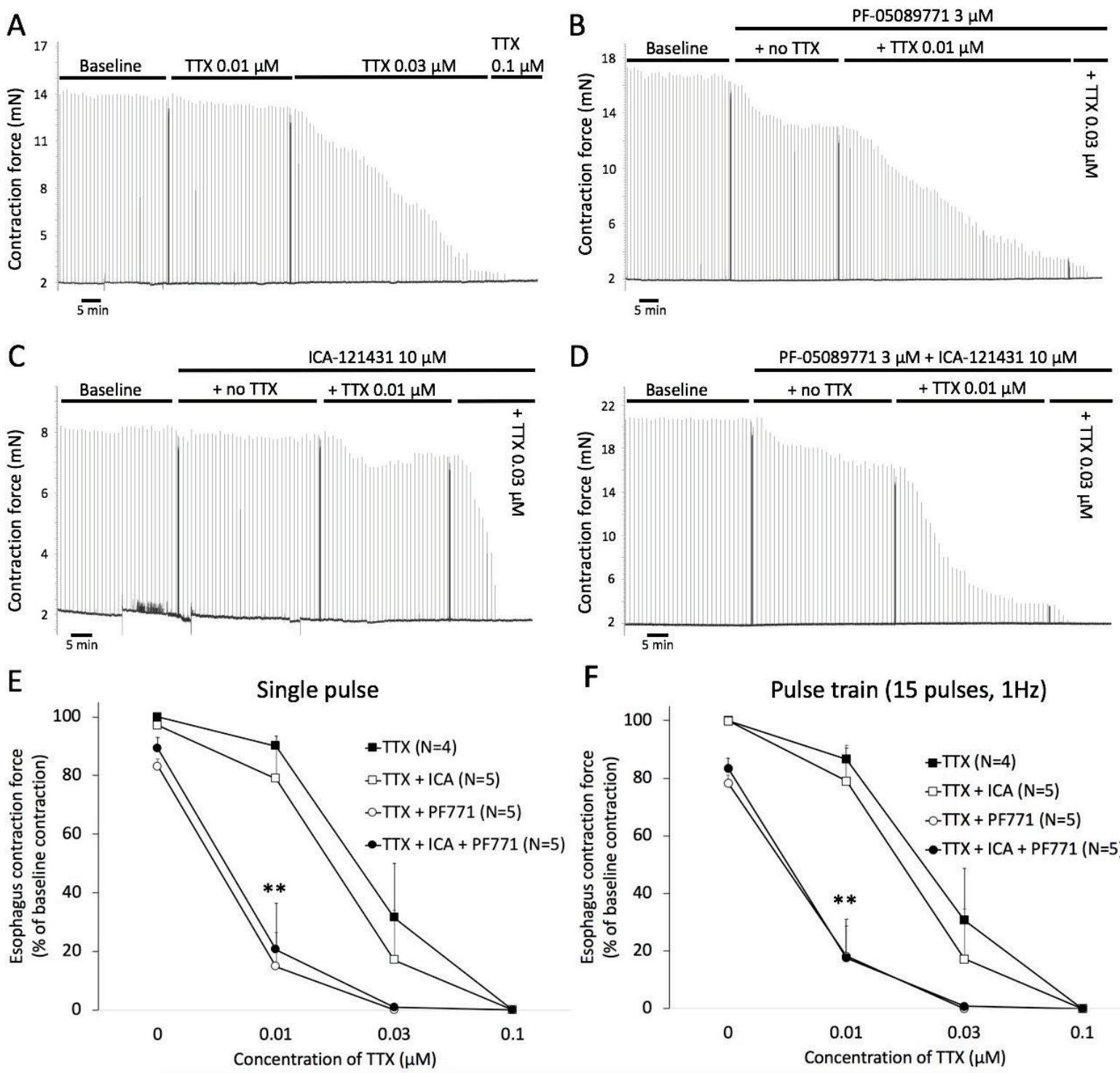

Fig. 2. The effect of $\mathrm{Na}_{\mathrm{v}} 1$ inhibitors on conduction in vagal motor fibers innervating esophageal striated muscle. Esophageal striated muscle contractions were evoked by electrical stimulation of the vagus nerve. Nav1 inhibitors were applied to de-sheathed vagus nerve (Fig. 1). (A-D) Examples of traces of each type of experiments. Contractions were evoked by a single pulse applied every $60 \mathrm{~s}$ and by a pulse train (1 Hz, 20 pulses) applied at the end of each incubation period (indicated by arrowheads). (E-F) Mean data. Note that TTX completely abolished the contraction and that the Nav1.7 inhibitor PF-05089771 (PF771), but not the Nav1.1/1.2/1.3 group blocker ICA-121431 (ICA), strongly potentiated the effect of TTX. As described in methods, the combination of Nav1 inhibitors containing $0.1 \mu \mathrm{M}$ concentration of TTX could be evaluated only when the combination of Nav1 inhibitors containing previous $0.03 \mu \mathrm{M}$ concentration of TTX did not abolish contraction (in 2, 2, 1 and 0 instances in TTX, TTX+ICA, TTX+PF771, TTX+PF771 experiments, respectively). Statistics: Single pulse at $0.01 \mu \mathrm{M}$ TTX One-way ANOVA $(P<0.01)$. 


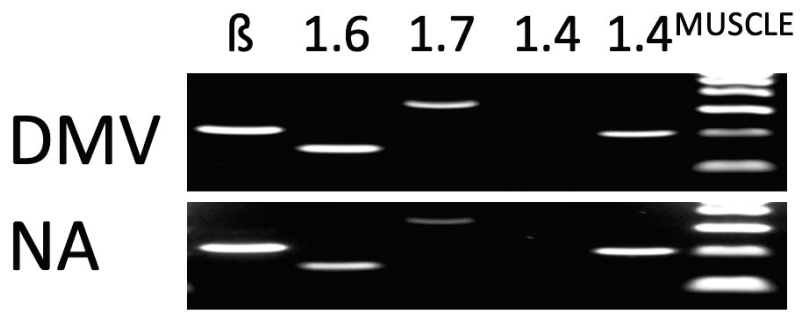

Fig. 3. Expression of candidate Nav1s mRNA in brainstem nuclei, which contain neurons projecting efferent motor fibers into the esophagus. Representative RT-PCR gels. Note that Nav1.6 and $\mathrm{Na}_{v} 1.7$, but not $\mathrm{Na}_{\mathrm{v}} 1.4$ were expressed in dorsal motor nucleus of the vagus nerve (DMV, N=4) and nucleus ambiguus (NA, $\mathrm{N}=4$ ). Positive control for Nav1.4 was obtained from striated muscle (labeled $1.4^{\mathrm{MUSCLE}}$ ). All bends have expected size.

\section{Discussion}

Our results support the conclusion that the conduction in motor fibers to esophageal striated muscle depends on $\mathrm{Na}_{\mathrm{V}} 1.7$ and $\mathrm{Na}_{\mathrm{V}} 1.6$. We provide direct evidence for $\mathrm{Na}_{\mathrm{V}} 1.7$ involvement by using the $\mathrm{Na}_{\mathrm{V}} 1.7$ selective inhibitor PF-05089771. However, PF-05089771 only partially inhibited the action potential conduction thereby revealing a substantial $\mathrm{Na}_{\mathrm{V}}$ 1.7-independent component. This component was TTX-sensitive and must be therefore mediated by one or a combination of the remaining TTX-sensitive channels $\mathrm{Na}_{\mathrm{V}} 1.1,1.2,1.3,1.4$ and/or 1.6. Firstly, we ruled out the role of $\mathrm{Na}_{\mathrm{V}} 1.1,1.2$ and 1.3 by using their group inhibitor ICA-121431. ICA-121431 had no effect alone and failed to exert any additional effect in the presence of TTX, PF-05089771 and their combination. Secondly, we ruled out the role of $\mathrm{Na}_{\mathrm{V}} 1.4$ by demonstrating the lack of $\mathrm{Na}_{\mathrm{V}} 1.4$ mRNA expression in the brainstem regions containing motor neurons innervating the esophagus. Thus, by ruling out $\mathrm{Na}_{\mathrm{V}} 1.1$ through 1.4 we conclude that in addition to $\mathrm{Na}_{\mathrm{V}} 1.7, \mathrm{Na}_{\mathrm{V}} 1.6$ mediates conduction in motor fibers to esophageal striated muscle.

In order to investigate the conduction in motor fibers to esophageal striated muscle we developed several novel modifications to the vagally-innervated esophagus preparation used previously by others (Bieger et al. 1985, Kerr et al. 1995). In particular, we delivered the $\mathrm{Na}_{\mathrm{V}} 1$ inhibitors selectively to the vagus nerve in a separate superfusion (Fig. 1). Therefore, these inhibitors were allowed to act only on the axons in the vagus nerve and not on the esophageal striated muscle (which expresses for example $\mathrm{Na}_{\mathrm{V}} 1.4$ ) or neuromuscular junctions (which may have different profile of $\mathrm{Na}_{\mathrm{V}} 1 \mathrm{~s}$ ). Therefore, any effect the $\mathrm{Na}_{\mathrm{V}} 1$ inhibitors had in our experiments were solely due to their action on vagal axons and hence on action potential conduction. We also removed the esophageal mucosa, which contains muscularis mucosae composed of smooth muscle, and therefore smooth muscle did not contribute to the contractions in our preparation. Previous studies have noted that the contractions of striated muscle are mediated by tubocurarine-sensitive nicotinic receptors, are insensitive to atropine, and abolished by tetrodotoxin, which is in agreement with our observations (Bartlet 1968, Bieger et al. 1985, Kerr et al. 1995, Kerr 2002, Zhang et al. 2018, Chen et al. 2019).

In our experiments, $\mathrm{Na}_{\mathrm{V}} 1$ inhibitors acting on the axons of vagal motor fibers decreased the force of esophageal striated muscle contraction evoked by electrical stimulation of the motor fibers. Because action potentials are conducted in an "all or none" manner, the decrease in the contraction force can be attributed to decreased number of motor axons conducting action potentials in the presence of $\mathrm{Na}_{\mathrm{V}} 1$ inhibitors. Specifically, PF-05089771 in the concentration of $3 \mu \mathrm{M}$ which completely blocks mouse $\mathrm{Na}_{\mathrm{V}} 1.7$ caused $17 \%$ inhibition of contraction. This observation indicates that at least some motor fibers were completely blocked by PF-05089771, i.e. that $\mathrm{Na}_{\mathrm{V}} 1.7$ is essential for conduction in at least some of the motor fibers. Furthermore, in the presence of PF-05089771 the concentration of TTX required to inhibit contraction by at least $70 \%$ was reduced 3-fold from $0.03 \mu \mathrm{M}$ to $0.01 \mu \mathrm{M}$. This indicates that additional motor fibers also use $\mathrm{Na}_{\mathrm{V}} 1.7$ to support (partially) conduction, because in the presence of PF-05089771 lower concentration of TTX was sufficient to block the remaining (i.e. PF-05089771-insensitive) $\mathrm{Na}_{\mathrm{V}} 1$ channels to block the conduction. Collectively, these data provide support for our conclusion that $\mathrm{NaV} 1.7$ is involved in the conduction of motor fibers to esophageal striated muscle. On the other hand, even in the presence of PF-05089771 $3 \mu \mathrm{M}$ which completely blocks $\mathrm{Na}_{\mathrm{V}} 1.7$ and ICA-121431 $10 \mu \mathrm{M}$ which completely blocks $\mathrm{Na}_{\mathrm{V}} 1.1,1.2$ and 1.3 a substantial TTX-sensitive contraction was preserved. Given the expected lack of the expression of $\mathrm{Na}_{\mathrm{V}} 1.4$ in brainstem areas containing neurons projecting motor fibers to the esophagus, these data support the conclusion that the only remaining TTX-sensitive channel $\mathrm{Na}_{\mathrm{V}} 1.6$ is also involved in the conduction of motor fibers to esophageal striated muscle.

Our conclusion that $\mathrm{Na}_{\mathrm{V}} 1.6$ and $\mathrm{Na}_{\mathrm{V}} 1.7$ are involved in the conduction in motor fibers to esophageal striated muscle has implications in predicting the 
potential side effects on esophageal motility of $\mathrm{Na}_{\mathrm{v}} 1$ inhibitors developed for treatment of pain. $\mathrm{Na}_{\mathrm{v}} 1.7$ is one of the major $\mathrm{Na}_{\mathrm{V}} 1 \mathrm{~s}$ targets for pain (Bennett et al. 2019). Our data (Fig. 2) indicate that even a complete block of $\mathrm{Na}_{\mathrm{V}} 1.7$ had only a limited effect (an inhibition by less than $20 \%$ ) on the conduction. Therefore, the expected side effects of $\mathrm{Na}_{\mathrm{v}} 1.7$ inhibitor on esophageal motility are likely to be limited. In contrast, $\mathrm{Na}_{\mathrm{V}} 1.6$, although expressed in many pain-mediating $\mathrm{C}$-fiber nociceptors, appears to have less potential as a pain treatment target (Bennett et al. 2019). However, there are certain clinical conditions (such as pain induced by chemotherapeutic agent Oxaliplatin) in which the inhibition of $\mathrm{Na}_{\mathrm{V}} 1.6$ is predicted to provide a pain relief. Our results offer a caveat that such $\mathrm{Na}_{\mathrm{V}} 1.6$ inhibitors may have substantial effects on esophageal motility. This possibility remains to be tested when the selective $\mathrm{Na}_{\mathrm{V}} 1.6$ inhibitors become available.

\section{Conflict of Interest}

There is no conflict of interest.

\section{Acknowledgements}

This study was supported by Vega grant 1/0020/19.

\section{References}

ALEXANDROU AJ, BROWN AR, CHAPMAN ML, ESTACION M, TURNER J, MIS MA, WILBREY A, PAYNE EC, GUTTERIDGE A, COX PJ, DOYLE R, PRINTZENHOFF D, LIN Z, MARRON BE, WEST C, SWAIN NA, STORER RI, STUPPLE PA, CASTLE NA, HOUNSHELL JA, ET AL.: Subtype-selective small molecule inhibitors reveal a fundamental role for Nav1.7 in nociceptor electrogenesis, axonal conduction and presynaptic release. PLoS One 11: e0152405, 2016. https://doi.org/10.1371/journal.pone.0152405

BARTLET AL: The effect of vagal stimulation and eserine on isolated guinea-pig oesophagus. Q J Exp Physiol Cogn Med Sci 53: 170-174, 1968. https://doi.org/10.1113/expphysiol.1968.sp001956

BENNETT DL, CLARK AJ, HUANG J, WAXMAN SG, DIB-HAJJ SD: The role of voltage-gated sodium channels in pain signaling. Physiol Rev 99: 1079-1151, 2019. https://doi.org/10.1152/physrev.00052.2017

BIEGER D, TRIGGLE C: Pharmacological properties of mechanical responses of the rat oesophageal muscularis mucosae to vagal and field stimulation. Br J Pharmacol 84: 93-106, 1985.

CATTERALL WA: Voltage-gated sodium channels at 60: structure, function and pathophysiology. J Physiol 590: 2577-2589, 2012. https://doi.org/10.1113/jphysiol.2011.224204

CHEN Z, GU D, FAN L, ZHANG W, SUN L, CHEN H, DONG R, LAI K: Neuronal activity of the medulla oblongata revealed by manganese-enhanced magnetic resonance imaging in a rat model of gastroesophageal refluxrelated cough. Physiol Res 68: 119-127, 2019. https://doi.org/10.33549/physiolres.933791

KERR KP: The guinea-pig oesophagus is a versatile in vitro preparation for pharmacological studies. Clin Exp Pharmacol Physiol 29: 1047-1054, 2002. https://doi.org/10.1046/j.1440-1681.2002.03774.x

KERR KP, MITCHELSON F, COUPAR IM: Vagal nerve stimulation of the guinea-pig oesophagus. Acta Physiol Scand 154: 213-220, 1995. https://doi.org/10.1111/j.1748-1716.1995.tb09903.x

KOCMALOVA M, KOLLARIK M, CANNING BJ, RU F, ADAM HERBSTSOMER R, MEEKER S, FONQUERNA S, APARICI M, MIRALPEIX M, CHI XX, LI B, WILENKIN B, MCDERMOTT J, NISENBAUM E, KRAJEWSKI JL, UNDEM BJ: Control of neurotransmission by NaV1.7 in human, guinea pig, and mouse airway parasympathetic nerves. J Pharmacol Exp Ther 361: 172-180, 2017. https://doi.org/10.1124/jpet.116.238469

MCCORMACK K, SANTOS S, CHAPMAN ML, KRAFTE DS, MARRON BE, WEST CW, KRAMBIS MJ, ANTONIO BM, ZELLMER SG, PRINTZENHOFF D, PADILLA KM, LIN Z, WAGONER PK, SWAIN NA, STUPPLE PA, DE GROOT M, BUTT RP, CASTLE NA: Voltage sensor interaction site for selective small molecule inhibitors of voltage-gated sodium channels. Proc Natl Acad Sci U S A 110: E2724-E2732, 2013. https://doi.org/10.1073/pnas. 1220844110

MCGOVERN AE, MAZZONE SB: Characterization of the vagal motor neurons projecting to the Guinea pig airways and esophagus. Front Neurol 1: 153, 2010. https://doi.org/10.3389/fneur.2010.00153

NEUHUBER WL, RAAB M, BERTHOUD HR, WORL J: Innervation of the mammalian esophagus. Adv Anat Embryol Cell Biol 185: 1-73, back cover, 2006. 
SWAIN NA, BATCHELOR D, BEAUDOIN S, BECHLE BM, BRADLEY PA, BROWN AD, BROWN B, BUTCHER KJ, BUTT RP, CHAPMAN ML, DENTON S, ELLIS D, GALAN SRG, GAULIER SM, GREENER BS, DE GROOT MJ, GLOSSOP MS, GURRELL IK, HANNAM J, JOHNSON MS, ET AL.: Discovery of clinical candidate 4-[2-(5-Amino-1H-pyrazol-4-yl)-4-chlorophenoxy]-5-chloro-2-fluoro-N-1,3-thiazol-4-ylbenzenesulfonamide (PF-05089771): design and optimization of diaryl ether aryl sulfonamides as selective inhibitors of NaV1.7. J Med Chem 60: 7029-7042, 2017. https://doi.org/10.1021/acs.jmedchem.7b00598

ZHANG L, ZHAO W, ZHAO C, JIN H, WANG B, WANG B: Study on effects of electrical stimulation on rabbit esophageal body motility in vivo. Physiol Res 67: 275-282, 2018. https://doi.org/10.33549/physiolres.933652 